\title{
Effects of short-term inhaled fluticasone on oxidative burst of sputum cells in cystic fibrosis patients
}

\author{
N. Dauletbaev ${ }^{+}$, K. Viel ${ }^{+}$, J. Behr*, S. Loitsch ${ }^{+}$, R. Buhl ${ }^{\S}$, T.O.F. Wagner ${ }^{+}$, J. Bargon $^{+}$
}

\begin{abstract}
Effects of short-term inhaled fluticasone on oxidative burst of sputum cells in cystic fibrosis patients. N. Dauletbaev, K. Viel, J. Behr, S. Loitsch, R. Buhl, T.O.F Wagner, J. Bargon. (C) ERS Journals Ltd 1999.

ABSTRACT: Inhaled corticosteroids have been proposed to decrease pulmonary inflammation in cystic fibrosis (CF). In this study the effects of therapy with inhaled fluticasone on clinical and sputum outcomes (leukocyte count, activity of myeloperoxidase, superoxide anion release) in adult $\mathrm{CF}$ patients were investigated in an open label design.

Twenty-six stable patients (median \pm sD forced expiratory volume in one second (FEV1) $58.1 \pm 19.9 \%$ pred.) were randomly assigned to the study group (500 $\mu \mathrm{g}$ b.i.d., for three weeks) or the control group ( $n=14$; nonsteroid medication). Sputum samples were obtained during inhalation of hypertonic saline (3\%, 20 min), which was found not to alter the investigated sputum parameters.

No significant changes in clinical parameters, sputum leukocyte count, activity of myeloperoxidase, and baseline superoxide anion release where observed following therapy. Surprisingly, stimulated superoxide anion release increased significantly after therapy $\left(34.1 \pm 17.7\right.$ versus $25.2 \pm 17.4 \mathrm{nmol} \cdot \mathrm{hr}^{-1} \cdot 10^{6}$ cells, $\left.\mathrm{p}<0.03\right)$ and exceeded spontaneous variability of this parameter $(\mathrm{p}=0.02$ versus control group).

In conclusion, in adult cystic fibrosis patients short-term fluticasone therapy had no evident effect on clinical and sputum parameters. Further investigations are necessary to evaluate whether the observed up-regulation of oxidative capacity of inflammatory cells is of concern or benefit in these patients.

Eur Respir J 1999; 14: 1150-1155.
\end{abstract}

Divisions of Pulmonary Medicine Uni-
versity Hospitals of ${ }^{+}$Frankfurt, *Munich, ${ }^{\S}$ Mainz, Germany.

Correspondence: J. Bargon

Division of Pulmonary Medicine

Dept of Internal Medicine

Frankfurt University Hospital

Theodor-Stem-Kai 7

60590 Frankfurt/Main

Germany

Fax: 496963017391

Keywords: Cystic fibrosis

corticosteroids

induced sputum

oxidative burst

Received: February 81999

Accepted after revision August 151999

Supported by Mukoviszidose e. V. Bonn and Deutscher Akademischer Austauschdienst
Cystic fibrosis $(\mathrm{CF})$ lung disease still represents the major challenge in the treatment of CF patients. It significantly affects the quality of life and ultimately leads to a fatal outcome. Despite increases in knowledge about the pathogenesis of CF lung disease, the excessive pulmonary neutrophil-dominated inflammation is still the main factor leading to the progressive lung damage in $\mathrm{CF}[1,2]$.

Corticosteroids are very potent anti-inflammatory drugs, also available for inhalation. In allergic asthma, therapy with inhaled corticosteroids significantly reduces airway inflammation and improves clinical outcome [3, 4]. Though inhaled corticosteroids would probably not be able to completely reverse chronic destructive processes in $\mathrm{CF}$ lung, these drugs might slow down the otherwise rapid decline of lung function. Up to now, several studies have been performed to evaluate the clinical efficacy of inhaled corticosteroids in the treatment of CF lung disease [5-8], and only small, or no, benefits from the use of these drugs in CF patients has been shown. It has been suggested that bulky and viscous CF sputum might hinder inhaled corticosteroids from reaching the pulmonary epithelium [5].

It was hypothesized that the effects of inhaled corticosteroids might be demonstrated with regard to airway inflammatory cells represented in CF sputum. In the present study the authors examined the effects of short-term therapy with high-dosed inhaled fluticasone on parameters of airway inflammation which compromised: 1) leukocyte count in sputum; 2) superoxide anion $\left(\mathrm{O}_{2}\right)$ production by inflammatory sputum cells; and 3 ) activity of myeloperoxidase in sputum samples. In addition, the authors compared the dynamics of inflammatory parameters in the course of treatment with spontaneous variation of these parameters, which was observed in a group of CF patients receiving nonsteroid medications. Finally, the dynamics of clinic and lung function parameters during the treatment were examined.

\section{Material and methods}

Study group and study design

Twenty-six stable adult CF patients (13 females, 13 males; median age (range) 26 (16-38) yrs) participated in this randomized, open-labelled, prospective, parallel study. In all patients, the diagnosis of CF was confirmed by repeated positive sweat tests. None of the patients previously used oral corticosteroids; 6 patients who used inhaled corticosteroids, discontinued the use of steroids 6 weeks prior to the study. All patients gave written consent. The study design was approved by the Ethics Committee of the Frankfurt University Hospital.

On day 0 , routine physical examination and spirometric measurements forced vital capacity (FVC), forced expiratory volume in one second (FEV1), mid-expiratory flow 
(MEF25-75) were performed. In addition, sputum samples that patients produced during inhalation of hypertonic saline $(3 \% \mathrm{NaCl}, 20 \mathrm{~min})$ were obtained. Prior to the study, a random number row was generated, and patients with even and odd numbers were consecutively divided into the study and control groups. Patients in the study group were instructed on how to use a dry powder inhaler and started with inhaled fluticasone propionate $(500 \mathrm{mg}$ b.i.d., (Flutide( $\mathrm{R})$; GlaxoWellcome, Bad Oldesloe, Germany) for the next 3 weeks. If necessary, patients of the study group continued the use of nonsteroid medications ( $\beta$-agonists, prophylactic antibiotics, and deoxyribonuclease (DNase), and the dosages stayed unchanged throughout the study. Patients of the control group maintained the same standard nonsteroid therapy during the observation period. The examinations and procedures were repeated during the next visit to the clinic (day 22). Patients were asked to bring the inhalers in order to check the use of medication. Criteria of efficacy of therapy were: 1) subjective improvement of symptoms of CF lung disease (shortness of breath, coughing, sputum production, and use of short-acting inhaled $\beta_{2}$-agonists over the study period) as evaluated by a questionnaire; 2) improvement of lung function parameters; and 3) evaluation of sputum outcome measurements.

\section{Sputum measurements}

Spontaneously produced CF sputum is extremely viscous and causes difficulties in obtaining the sputum cells. Therefore, it was decided to evaluate induced sputum collected during inhalation of hypertonic saline, which is not as viscous as spontaneously produced sputum. Spontaneous and induced sputum samples from CF patients were obtained and compared prior to the study, in order to assure that inhalation of hypertonic saline itself does not alter morphological and functional cellular parameters.

Spontaneously produced and induced sputum samples were stored at $+4^{\circ} \mathrm{C}$ and processed within $2 \mathrm{~h}$ after being obtained. After diluting with two volumes of phosphatebuffered saline (PBS) and vigorous vortexing, samples were filtered through a single sheet of gauze and centrifuged $\left(300 \times g, 25^{\circ} \mathrm{C}, 15 \mathrm{~min}\right)$. Supernatants were collected and stored at $-80^{\circ} \mathrm{C}$ until assayed. Cell pellets were resuspended in 5-10 mL Hank's balanced salt solution (HBSS; Sigma-Aldrich Chemie GmbH, Steinheim, Germany), and total cell amounts and cell viability (Trypan blue exclusion) were evaluated. Final cell concentrations usually ranged $1-5 \times 10^{6}$ cells $\cdot \mathrm{mL}^{-1}$. An aliquot of the cells was cytospun $\left(57 \times g, 25^{\circ} \mathrm{C}, 10 \mathrm{~min}\right)($ Cytospin $2 \AA$; Shandon Instruments, Frankfurt/Main, Germany) and stained with a May-Grünwald-Giemsa dye. To evaluate differential cell counts (epithelial cells, neutrophils, macrophages, lymphocytes, and eosinophils), 400 random nonsquamous cells were counted independently by two expert readers who were unaware of the expected outcomes.

The capacity of sputum cells to produce $\mathrm{O}_{2}^{-}$was determined by a superoxide dismutase (SOB) inhibitable ferricytochrome $c$ reduction assay $[9,10]$. All reagents were purchased from Sigma-Aldrich Chemie $\mathrm{GmbH}$. Sputum cells were washed with HBSS and resuspended to obtain a cell concentration of $1 \times 10^{6}$ cells $\cdot \mathrm{mL}^{-1}$. The cell suspensions consisted of $>90 \%$ neutrophils as assessed by cytological investigations. For the assay, cyto- chrome $c$ was diluted in prewarmed HBSS and given to cells at a final concentration of $80 \mu \mathrm{M}$. Cells were incubated for $30 \mathrm{~min}$ at $37^{\circ} \mathrm{C}$. After the incubation, the absorbance rate of the cell-free supernatant was determined at $550 \mathrm{~nm}$. A negative control (non- $\mathrm{O}_{2}{ }^{-}$induced cytochrome $c$ reduction) comprised of cells incubated with $80 \mu \mathrm{M}$ cytochrome $c$ and SOD (final concentration 2 $\left.\mathrm{mg} \cdot \mathrm{mL}^{-1}\right)$. Stimulated $\mathrm{O}_{2}^{-}$production by sputum cells was evaluated after incubation the cells with cytochrome $c$ and phorbol ester (final concentration $100 \mathrm{ng} \cdot \mathrm{mL}^{-1}$ ). Spontaneous and stimulated $\mathrm{O}_{2}^{-}$release, and negative control reactions were run in parallel. The amounts of $\mathrm{O}_{2}{ }^{-}$ released spontaneously or after stimulation with phorbol ester were calculated by subtracting the absorbance rates obtained in the presence of SOD. The results were expressed as nmol O${ }_{2}^{-}$released in an hour by $1 \times 10^{6}$ cells.

The activity of myeloperoxidase (MPO) was determined in sputum supernatants diluted with 10 volumes PBS using tetramethylbenzidine as a substrate [11]. All measurements were performed in duplicate.

In addition, sputum samples were subjected to microbiological analysis in order to assess bacterial load of the samples.

\section{Statistical analysis}

All data are shown as median (SD) or median (range) where appropriate. Spontaneously produced and induced sputum samples were compared as independent variables. Other clinical, lung function, and sputum outcomes were compared as paired samples (day 22 versus day 0 ). Since data were not-normally distributed, nonparametric methods were used to analyse the differences. A difference at $p$ value $<0.05$ was considered significant.

\section{Results}

Patients who participated in this study showed typical features of CF lung disease (FEV1 1.96 (0.85) L, 58.1 $(19.9) \%$ pred) and absence of acute exacerbation (Creactive protein (CRP) $\left.0.65(1.0) \mathrm{mg} \cdot \mathrm{dL}^{-1}\right)$. Twenty-one patients (10 and 11 patients of the study and control group respectively) showed colonization with Pseudomonas species, with median duration of colonization of 7 (6) yrs. No patient had Burkholderia cepacia infection. Nonsteroid medications included DNase (4 and 5 patients of the study and control group. respectively) and prophylactic antibiotics (oral antibiotics: 5 and 7 patients; inhaled antibiotics: 6 and 6 patients of the study and control group, respectively). The dosages of all nonsteroid medications remained unchanged for some weeks prior to and throughout the study period.

Three patients with history of bronchial hyperresponsiveness responded to inhalation of hypertonic saline with decline of FEV1 of $>15 \%$ of baseline $(-18.3,-24.4$, and $33.3 \%$ ). Sputum induction, however, was generally well tolerated, and only an insignificant decrease of lung function (-6.0 (9.0)\% of baseline; $p>0.3)$ was observed in the $\mathrm{CF}$ group. There was no relationship between baseline lung function and decline of FEV1 after sputum induction (p>0.2). 


\section{Clinical parameters}

Fluticasone propionate was well tolerated by all patients, with no adverse effects reported. The therapy did not result in a significant improvement of disease symptoms as was evaluated by analysing patients' questionnaires $(p>0.5$; data not shown). Additionally, no improvement of lung function parameters was observed following therapy. Thus, the level of FEV1 on day $22(53.2(22.9) \%)$ was comparable with the one on day $0(55.8(21.6) \%$; $p>0.1)$. This was true for other investigated lung function parameters as well ( $p>0.2)$. The dynamics of lung function parameters in the course of treatment did not exceed spontaneous variation observed in the control group patients (day $22 \mathrm{FEV} 1$ 56.3 (20.3)\% versus day 0 FEV1 56.7 (25.8)\%; p>0.2).

\section{Sputum analysis}

Spontaneous and induced sputum samples were similar in cell viability and differential cell patterns $(p>0.5$, all comparisons; table 1). Thus, sputum cell population consisted of $>90 \%$ neutrophils (table 1), whereas the percentages of other cells (macrophages, eosinophils, lymphocytes, and epithelial cells) were low. Of great importance is the fact that sputum induction did not alter the activity of cells as was demonstrated by investigation of baseline and stimulated $\mathrm{O}_{2}^{-}$release ( $p>0.5$, both comparisons; table 1).

After treatment with fluticasone, volumes of induced sputum were similar to those obtained prior to therapy ( $p>0.3$, all comparisons; table 2). In addition, there was only an insignificant change in leukocyte count (1.0 (2.4) versus $1.3(10.9) \times 10^{6} \cdot \mathrm{mL}^{-1}$ on day 0$)$ and percentage of neutrophils (91.0 (7.6) versus $93.0(10.2) \%$ on day 0 , table $2 ; \mathrm{p}>0.1$, both comparisons). In the control group, leukocyte counts and differential cell patterns varied only insignificantly as well ( $p>0.2$, both comparisons; table 2 ).

Sputum cells spontaneously released large amounts of $\mathrm{O}_{2}$ (study group 8.7 (5.0), control group 6.5 (5.1) nmol. $\mathrm{hr}^{-1} \cdot 10^{6}$ cells, $\mathrm{p}>0.1$; table 2 , fig. 1 ). The cells were, however, still capable of producing more $\mathrm{O}_{2}{ }^{-}$upon stimulation. Thus, in both groups, incubation of sputum cells with phorbol ester resulted in $\sim 3$-fold increase of $\mathrm{O}_{2}{ }^{-}$production (study group 25.2 (17.4), control group 18.6 (19.3)

Table 1. - Comparable data of spontaneously and induced cystic fibrosis (CF) sputum.

\begin{tabular}{lcr}
\hline & $\begin{array}{c}\text { Spontaneously } \\
\text { produced } \\
\text { sputum }\end{array}$ & $\begin{array}{c}\text { Induced } \\
\text { sputum }\end{array}$ \\
\hline Cell viability & $84.0 \pm 3.0$ & $87.0 \pm 2.6$ \\
Neutrophils & $95.0 \pm 10.1$ & $93.0 \pm 8.2$ \\
Macrophages & $3.0 \pm 3.3$ & $4.0 \pm 3.0$ \\
Eosinophils & $1.0 \pm 1.0$ & $1.0 \pm 1.1$ \\
Epithelial cells & $2.0 \pm 8.2$ & $4.0 \pm 7.3$ \\
Baseline $\mathrm{O}_{2}^{-}$release & $10.3 \pm 6.4$ & $10.8 \pm 4.2$ \\
nmol. $\mathrm{h}^{-1} \cdot 10^{6}$ cells & & \\
Stimulated $\mathrm{O}_{2}^{-}$release & $25.5 \pm 21.2$ & $27.3 \pm 19.9$ \\
nmol. $\mathrm{h}^{-1} \cdot 10^{6}$ cells & & \\
\hline
\end{tabular}

Data are presented as median \pm SD percentage, unless indicated otherwise. Both sputum samples were similar in cell viability, differential cell pattern, and oxidative activity of the cells $(p>0.5)$. nmol $\cdot \mathrm{hr}^{-1} \cdot 10^{6}$ cells, $\mathrm{p}=0.1$; table 2 ). On day 22 , the baseline $\mathrm{O}_{2}{ }^{-}$production remained almost at the same level in both groups (study group 8.2 (5.0), control group 7.1 (5.0) $\mathrm{nmol} \cdot \mathrm{hr}^{-1} \cdot 10^{6}$ cells, $\mathrm{p}>0.5$, both comparisons; table 2, fig. 1). Surprisingly, sputum cells of most (9 of 12) patients treated with inhaled corticosteroids were more capable of oxidative burst, and this difference was true for the whole group: upon stimulation with phorbol ester, the sputum cells produced significantly more $\mathrm{O}_{2}{ }^{-}$in comparison to initial levels (34.1 (17.7) versus 25.2 (17.4) nmol. $\mathrm{hr}^{-1} \cdot 10^{6}$ cells, $\mathrm{p}<0.03$; table 2 , fig. 1$)$. Furthermore, this overproduction of $\mathrm{O}_{2}{ }^{-}$exceeded the spontaneous variability of this parameter observed in patients of the control group ( $\mathrm{p}=0.02$; table 2 , fig. 1$)$. No clinical or sputum parameter was associated with an increased capacity of sputum cells for respiratory burst.

The variations in activity of MPO, which were observed in both study and control groups, were not significant ( $\mathrm{p}>$ 0.5 , both comparisons; table 2 ).

\section{Discussion}

Since neutrophil-dominated inflammation plays a key role in the pathogenesis of CF lung disease, anti-inflammatory drugs, which control or reverse this process, would be helpful in the treatment of CF. Unfortunately, these drugs are not yet available. Thus, the use of oral corticosteroids has been shown to be of benefit in these patients [12], but was accompanied by significant adverse effects, and is not routinely used. To date, some studies have been performed to investigate the effects of inhaled corticosteroids in $\mathrm{CF}$ on clinical parameters as disease symptoms, lung function, and airway hyperreactivity [5-8]. However, few data exist about the mechanisms of corticosteroid action on CF pulmonary inflammation. In the present study the authors examined the in vivo effects of a highdose inhaled corticosteroid (fluticasone) on the activity of airway inflammatory cells represented in CF sputum.

The majority of the patients who participated in this study demonstrated evidence of bronchial obstruction, which was mostly very little or not reversible. Inhalation of hypertonic saline was used to initiate sputum production, in order to obtain large enough amounts of inflammatory cells to perform the investigations. In contrast to asthma patients with a comparable degree of bronchial obstruction [13], CF individuals tolerated sputum induction well, demonstrating no significant change from baseline FEV1 after the procedure. Importantly, sputum induction did not alter investigated parameters as was shown by examining sputum differential cell patterns and oxidative burst of sputum cells. In order to minimize the influence of other factors on study outcomes, the patients in both groups received a standardized nonsteroid therapy. Furthermore, since inhaled antibiotics and DNase were reported to interfere with pulmonary inflammation, the patients' medications in both groups remained unchanged for some weeks before and throughout the study period. Finally sputum analysis was performed by persons unrelated to this study.

No adverse effects of therapy with fluticasone were observed, and the patients could easily integrate this treatment into their regular therapy. 
Table 2. - Sputum outcomes in the study and control groups

\begin{tabular}{lcccc}
\hline & \multicolumn{2}{c}{ Study group } & \multicolumn{2}{c}{ Control group } \\
\cline { 2 - 3 } & Day 0 & Day 22 & Day 0 & Day 22 \\
\hline Volume $\mathrm{mL}$ & $14 \pm 7.0$ & $15 \pm 9.5$ & $10 \pm 8.2$ & $11 \pm 6.0$ \\
Cells $10^{6} \cdot \mathrm{mL}^{-1}$ & $1.0 \pm 2.4$ & $1.3 \pm 10.9$ & $3.1 \pm 4.7$ & $4.1 \pm 14.2$ \\
Viability & $88.1 \pm 10.0$ & $90 \pm 4.4$ & $87.4 \pm 7.1$ & $91.0 \pm 8.4$ \\
Neutrophils & $93.0 \pm 10.2$ & $91.0 \pm 7.6$ & $90.5 \pm 8.4$ & $91.5 \pm 7.9$ \\
Macrophages & $3.0 \pm 3.8$ & $3.0 \pm 3.9$ & $3.0 \pm 3.5$ & $3.5 \pm 2.9$ \\
Eosinophils & $1.0 \pm 0.8$ & $1.0 \pm 0.9$ & $1.0 \pm 2.0$ & $1.0 \pm 0.8$ \\
Lymphocytes & $0.0 \pm 0.0$ & $0.0 \pm 0.0$ & $1.0 \pm 1.3$ & $1.0 \pm 1.2$ \\
Epithelial cells & $2.0 \pm 8.4$ & $5.0 \pm 7.2$ & $1.0 \pm 9.3$ & $0.0 \pm 3.8$ \\
O $_{2}^{-}$release nmol $\cdot \mathrm{h}^{-1} \cdot 10^{6}$ cells & & & & \\
Baseline & $8.7 \pm 5.0$ & $8.2 \pm 5.0$ & $6.5 \pm 5.1$ & $7.1 \pm 5.0$ \\
Stimulated & $25.2 \pm 17.4$ & $34.1 \pm 17.7^{\S}$ & $18.6 \pm 19.3$ & $20.2 \pm 12.1$ \\
MPO mU·mL & $4.4 \pm 2.8$ & $6.0 \pm 3.5$ & $5.0 \pm 12.6$ & $7.1 \pm 5.7$ \\
\hline
\end{tabular}

Data are presented as median \pm SD percentage, unless indicated otherwise. ${ }^{\S}: \mathrm{p}<0.03$ (comparison to day 0 ).

Similar to previous studies [5-8], no apparent benefit of a short-term treatment with inhaled fluticasone in terms of clinical outcome and lung function parameters was observed. Indeed, there might be subgroups of the $\mathrm{CF}$ population who would more significantly respond to the treatment with inhaled corticosteroids. Airway hyperresponsiveness, marked lung function variability, and reversible bronchial obstruction might characterize such patients $[6,8,14]$. This issue was not addressed in the present study, since the authors concentrated on investigation of pulmonary inflammation in the course of ther-
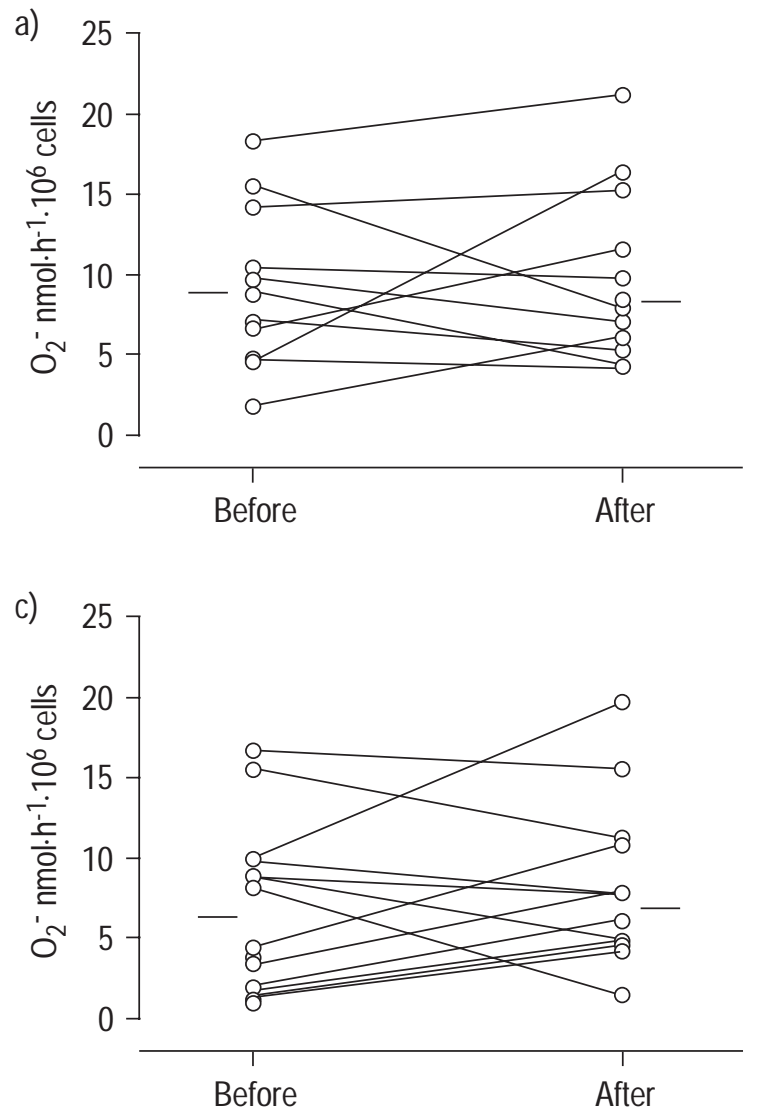

apy with inhaled corticosteroids. In addition, the duration of the therapy with inhaled corticosteroids (3 weeks) might be not long enough to result in a significant clinical improvement. Whilst planning this study it was assumed, however, that any effects of inhaled corticosteroids on sputum cell function might be demonstrated in this period of time, since the in vitro effects of these drugs have been observed within hours of application [15].

Inhaled corticosteroids are thought to be effective on two sites in the lung, with regard to the epithelium and the inflammatory cells $[3,16,17]$. For any effect on the
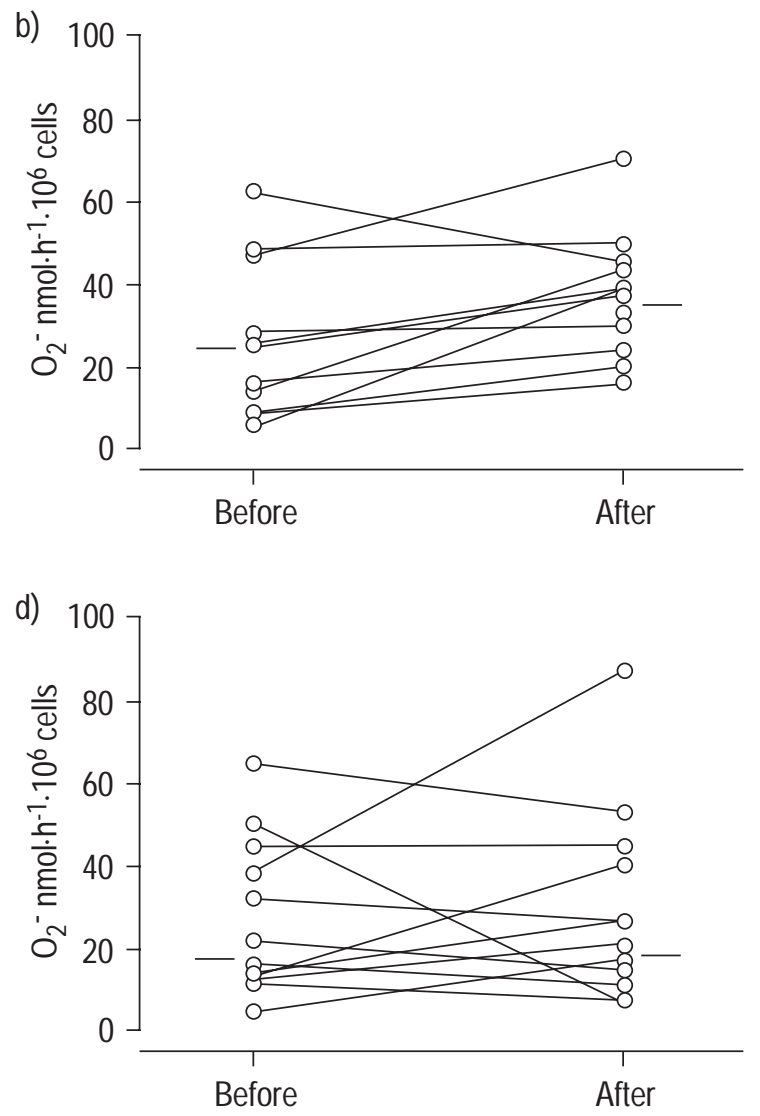

Fig. 1. - Individual data and median values (horizontal bars) of baseline (a and c) and stimulated (b and d) superoxide anion production by sputum cells before and after therapy with inhaled fluticasone (study group; a and b) or nonsteroid medication (control group; c and d). 
epithelium, corticosteroids have to reach the mucosal cells. In $\mathrm{CF}$, the high amount of viscous mucus may hinder the delivery of the drug to the epithelium. In this case, however, the effects of corticosteroids may be related to the activity of airway inflammatory cells. As far as is known, only some neutrophil functions can be influenced by steroids. Thus, steroids were reported to reduce the in vitro migrating activity of neutrophils with no influence on the phagocytic or degranulating activity of the cells [18-20]. Two recent studies which investigated the in vivo effects of inhaled corticosteroids in patients with chronic obstructive pulmonary disease (COPD) [21] and bronchiectasis [22] showed significant decreases in the leukocyte count and the percentage of neutrophils after therapy. In the current study, a significant change of these parameters after therapy with inhaled fluticasone was not found. This discrepancy might be due to the different study population (CF versus COPD or bronchiectasis). In CF, according to current concepts $[1,2]$, the gene mutation results in impaired regulation of airway surface fluid volume and/or ion composition which may result in the promotion of an inflammatory response of airway epithelium and an alteration in the activity of effector cells. Thus, a malfunction of neutrophils under these circumstances has been demonstrated [23]. This factor is absent in COPD and bronchiectasis. The present findings are, however, in good agreement with data from literature regarding the degranulating activity of neutrophils after therapy with corticosteroids [24]. Thus, MPO activity in the current study remained unchanged after therapy demonstrating that this activity of neutrophils was not influenced by fluticasone.

The in vitro data about the effects of steroids on neutrophils' oxidative burst are contradictory. Some authors reported suppression of radical production by neutrophils [12], whereas others did not find any change in $\mathrm{O}_{2}^{-}$production after application of steroids $[18,19]$. The present study is the first to evaluate the in vivo effects of inhaled corticosteroids on oxidative activity of airway inflammatory cells represented in sputum. No change in baseline $\mathrm{O}_{2}^{-}$production after fluticasone therapy was observed. There was, however, a significant increase of the cells' capacity for oxidative burst upon stimulation. This was true for the most (9 of 12) patients who received inhaled fluticasone, and the extent of this response significantly exceeded the variation by chance observed in the control group. There were no apparent clinical or sputum factors which might predict such a response to treatment with fluticasone. The mechanisms underlying this phenomenon remain thus far unclear. As yet the authors also have no means to definitively justify the overall clinical significance of this observation. Indeed, an increased capacity of inflammatory cells to undergo respiratory burst may indicate a threat of increasing oxidative burden in the CF lung. In the authors' opinion, however, this fact is more likely to be a manifestation of a normalizing of the bactericidal activity of inflammatory cells, since in CF a suboptimal response of these cells toward specific stimuli has been reported by several studies [25, 26].

In conclusion, after short-term therapy with high-dose fluticasone the authors did not find significant changes in most parameters of pulmonary inflammation examined in this study (sputum leukocyte count, baseline oxidative and degranulating activity of the cells). Although the signi- ficance of the study outcomes has some limitations due to the open unblinded study design, it is believed that the data obtained suggest that inhaled corticosteroids, at this dose, given over a short period of 3 weeks, do not effectively suppress the neutrophil-dominated pulmonary inflammation in cystic fibrosis. Nevertheless. in the authors' opinion inhaled corticosteroids have a potential role in cystic fibrosis, since oral steroids have been shown to be effective in this situation. Further longer-term trials, probably with higher doses of the drugs, are necessary to evaluate which subgroup of cystic fibrosis patients will benefit most from the use of inhaled corticosteroids. Future investigations have to determine whether the increased oxidative capacity of inflammatory cells, observed in the course of corticosteroid therapy, demonstrate the evidence of enhancement of oxidative stress or an increase of microbicidal activity in the cystic fibrosis lung.

Acknowledgements. The authors are grateful to B. Aulbach for excellent technical assistance.

\section{References}

1. Davis PB, Drumm M, Konstan MW. Cystic fibrosis. Am J Respir Crit Care Med 1996; 154: 1229-1256.

2. Pilewski JM, Frizzell RA. Role of CFTR in airway disease. Physiol Rev 1999; 79: S215-S255.

3. Barnes PJ. Current issues for establishing inhaled corticosteroids as the anti-inflammatory agents of choice in asthma. J Allergy Clin Immunol 1998; 101: S427-S433.

4. Boushey HA. Effects of inhaled corticosteroids on the consequences of asthma. J Allergy Clin Immunol 1998; 102 (Pt 2): S5-S16.

5. Balfour-Lynn IM, Klein NJ, Dinwiddle R. Randomized controlled trial of inhaled corticosteroids (fluticasone propionate) in cystic fibrosis. Arch Dis Child 1997; 77: 124130.

6. Bisgaard H, Pedersen SS, Nielsen KG, et al. Controlled trial of inhaled budesonide in patients with cystic fibrosis and chronic bronchopulmonary Pseudomonas aeruginosa infection. Am J Respir Crit Care Medr 1997; 156: 11901196.

7. Nikolaizik WH, Schöni MH. Pilot study to assess the effect of inhaled corticosteroids on lung function in patients with cystic fibrosis. J Pediatr 1996; 128: 271-274.

8. van Haren EHJ, Lammers J-WJ, Festen J, Heijerman HGM, Groot CAR, van Herwaarden CL. The effects of the inhaled corticosteroid budesonide on lung function and bronchial hyperresponsiveness in adult patients with cystic fibrosis. Respir Med 1995; 89: 209-214.

9. Buhl R, Jaffe HA, Holroyd KJ, et al. Activation of alveolar macrophages in asymptomatic HIV infected individuals. J Immunol 1993; 150: 1019-1028.

10. Markert M, Andrews PC, Babior BM. Measurement of $\mathrm{O}_{2}^{-}$production by human neutrophils. The preparation and assay of NADPH oxidase-containing particles from human neutrophils. Methods Enzymol 1984; 105: 358365 .

11. Suzuki K, Ota H, Sasagawa S, Sakatani T, Fujikura T. Assay method for myeloperoxidase in human polymorphonuclear leukocytes. Anal Biochem 1983; 132: 345352. 
12. Eigen H, Rosenstein BJ, FitzSimmons S, Schidlow DV. A multicenter study of alternate-day prednisone therapy in patients with cystic fibrosis. Cystic Fibrosis Foundation Prednisone Trial Group. J Pediatr 1995; 126: 515-523.

13. de la Fuente PT, Romagnoli M, Godard P, Bosquet J, Chanez P. Safety of inducing sputum in patients with asthma of varying severity. Am J Respir Crit Care Med 1998; 157: 1127-1130.

14. Conway SP, Watson A. Nebulized bronchodilators, corticosteroids, and rhDNase in adult patients with cystic fibrosis. Thorax 1997; 52: S64-S68.

15. Barnes PJ, Adcock IM. Transcriptional factors and asthma. Eur Respir J 1998; 12: 221-234.

16. Barnes PJ, Pedersen S, Busse WW. Efficacy and safety of inhaled corticosteroids. New developments. Am J Respir Crit Care Med 1998; 157: S1-S53.

17. van der Velden VH. Glucocorticoids: mechanisms of action and anti-inflammatory potential in asthma. Mediators Inflamm 1998; 7: 229-237.

18. Leech M, Hutchinson P, Holdsworth SR, Morand EF. Endogenous glucocorticoids modulate neutrophil migration and synovial P-selectin but not neutrophil phagocytic or oxidative function in experimental arthritis. Clin Exp Immunol 1998; 112: 383-388.

19. Llewellyn-Jones CG, Hill SL, Stockley RA. Effect of fluticasone propionate on neutrophil chemotaxis, superoxide generation, and extracellular proteolytic activity in vitro. Thorax 1994; 49: 207-212.
20. Salmon M, Koto H, Lynch OT, et al. Proliferation of airway epithelium after ozone exposure: effect of apocynin and dexamethasone. Am J Respir Crit Care Med 1998; 157: 970-977.

21. Confalonieri M, Mainardi E, Della Porta R, et al. Inhaled corticosteroids reduce neutrophilic bronchial inflammation in patients with chronic obstructive pulmonary disease. Thorax 1998; 53: 583-585.

22. Tsang KW, Ho PL, Lam WK, et al. Inhaled fluticasone reduces sputum inflammatory indices in severe bronchiectasis. Am J Respir Crit Care Med 1998; 158: 723-727.

23. Tager AM, Wu J, Vermeulen MW. The effect of chloride concentration on human neutrophil functions: potential relevance to cystic fibrosis. Am J Respir Cell Mol Biol 1998; 19: 643-652.

24. Keatings VM, Jatakanon A, Worsdell YM, Barnes PJ. Effects of inhaled and oral glucocorticoids on inflammatory indices in asthma and COPD. Am J Respir Crit Care Med 1997; 155: 542-548.

25. Frühwirth M, Ruedl C, Ellemunter H, Böck G, Wolf H. Flow-cytometric evaluation of oxidative burst in phagocytic cells of children with cystic fibrosis. Int Arch Allergy Immunol 1998; 117: 270-275.

26. Jensen ET, Kharazmi A, Hoiby N, Costerton JW. Some bacterial parameters influencing the neutrophil oxidative burst response to Pseudomonas aeruginosa biofilms. APMIS 1992; 100: 727-733. 